\title{
Alternations in Cholesterol and Fatty Acids Composition in Egg Yolk of Rhode Island Red x Fyoumi Hens Fed with Hemp Seeds (Cannabis sativa L.)
}

\author{
Suhaib Shahid, Naila Chand, Rifat Ullah Khan, \\ Syed Muhammad Suhail, and Nazir Ahmad Khan \\ Faculty of Animal Husbandry \& Veterinary Sciences, The University of Agriculture, Peshawar 25000, Pakistan \\ Correspondence should be addressed to Rifat Ullah Khan; rifatullahkhhan@gmail.com
}

Received 4 February 2015; Revised 3 May 2015; Accepted 3 August 2015

Academic Editor: Maria B. P. P. Oliveira

Copyright (c) 2015 Suhaib Shahid et al. This is an open access article distributed under the Creative Commons Attribution License, which permits unrestricted use, distribution, and reproduction in any medium, provided the original work is properly cited.

\begin{abstract}
The present study was designed to evaluate the influence of hemp seed (HS) supplementation on egg yolk cholesterol and fatty acid composition in laying hens. Sixty hens (Rhode Island Red x Fyoumi) were evenly distributed into four groups (three replicates per group) at the peak production (34 weeks). HS was included into the ration at the level of 0.0 (HS-0), 15 (HS-15), 20 (HS-20), and 25\% (HS-25) and continued the supplementation for consecutively three weeks. At the end of the experiment, three eggs per replicate were randomly collected and analyzed for egg yolk fatty acids and cholesterol profile. The statistical analysis of the result revealed that supplementation of HS-25 significantly $(P<0.05)$ decreased egg yolk total cholesterol, myristic $($ C14:0), palmitic (C16:0), and stearic (C18:0). Similarly, total as well as individual monounsaturated fatty acids decreased significantly $(P<0.05)$ while total and individual polyunsaturated fatty acids increased significantly in the HS-25. In addition, total omega-3 and omega-6 increased significantly in the HS-25 group. From the present result, we concluded that addition of HS at the rate of $25 \%$ to the diet of laying hens augmented the cholesterol and fatty acids profile in egg yolk.
\end{abstract}

\section{Introduction}

Healthy nutrition plays a major role in reducing morbidity and mortality around the globe. There is a strong relationship between the cholesterol profile of egg and the plasma cholesterol level [1]. Nutritionists have agreed that dietary polysaturated fatty acids (PUFA) of n-3 series play a crucial role in human health by promoting growth and development and demonstrate antithrombotic and antilipidemic effects [24]. The fatty acid composition of the egg may be influenced by the dietary composition offered to the laying hens [5, 6]. However, attempts to manipulate the total amount of fats in the egg through diet change have been marginally succeeded.

Hemp seed contains $25 \%$ protein, $30 \%$ carbohydrates, $10-15 \%$ fiber, and some trace minerals [7]. It also contains carotene and up to $35 \%$ oil [8-10]. HS contains a small quantity of delta-9-tetrahydrocannabinol (THC), a psychoactive compound [11] which provokes appetite $[12,13]$. HS oil contains $80 \%$ essential fatty acids (EFAs) including stearidonic acid, alpha-linolenic acid, gamma-linolenic acid, and linoleic acid. HS can be used efficiently without any fear of EFAs imbalance [14]. Previously Khan et al. [7] reported that supplementation of HS at the rate of $20 \%$ improved the weight gain in broiler. Konca et al. [13] found no effect of adding HS on the body weight, feed intake, and feed conversion ratio; however, serum low density lipoprotein (LDL) decreased in the Japanese quails.

Konca et al. [13] further reported that omega-3 fatty acid inhibits tumor and cancer growth, lowers cholesterol, helps normal blood pressure, and increases fats digestion. It also has anti-inflammatory characteristics and thus helps arthritis patients [14]. Omega- 6 and omega- 3 fatty acid ratio in HS is $3: 1$ which is good for human consumption $[14,15]$. Another advantage of the nutritional composition of HS is its gamma-linolenic acid content [14, 16]. Hemp seed lowers the egg cholesterol and modifies its fatty acid composition $[17,18]$. Intake of dietary fats and its effect on health are 
a major concern in nutrition research. In the particular cases where the intake of beneficial fatty acids is low because of decreased acceptability and accessibility, consumption of healthful fatty acids could be improved by consuming cheap and less expensive poultry products. A diet based on healthy profile of fatty acids is being recommended to fight heart and associated diseases. To date no information is available on the effect of feeding hemp seed on cholesterol and fatty acids profile of egg yolk in Rhode Island Red x Fyoumi laying hen. Due to the healthy profile of fatty acids in the HS, this study was planned to find its effect on the cholesterol and fatty acid profile of eggs in laying hens.

\section{Materials and Methods}

This experiment was approved by the Departmental Board of Studies for Methodology, involving bird welfare and standard laboratory protocols. The experiment was conducted at the Poultry Farm, Department of Poultry Science, The University of Agriculture, Peshawar.

2.1. Experimental Design and Management of Birds. Sixty hens (Rhode Island Red x Fyoumi) during the peak production ( 4 weeks) were randomly divided into four groups. Each group was replicated thrice with five birds per replicate. Standard management practices were adopted to ensure welfare of the birds. Light, feed, and water were given according to the standard requirements during the five-week experimental period including seven days of adaptation period. Hemp seeds were acquired from the local market and included in the ration at the level of 0.0 (HS-0), 15 (HS-15), 20 (HS-20), and $25 \%$ (HS-25). All the diets were isocaloric and isonitrogenous (Table 1). Hemp seeds were fed to the birds for consecutively three weeks. During the third week, three eggs per replicate were collected and subjected to analysis of fatty acid and cholesterol profile.

2.2. Cholesterol Analysis. Egg yolks were pooled from 3 eggs in each replicate per week and were frozen before further processing. Lipids were extracted from the yolk by using chloroform: methanol mixture $(2: 1 \mathrm{v} / \mathrm{v})$ [19]. Briefly, one gram of egg yolk was mixed with $20 \mathrm{~mL}$ of Folch solution (chloroform and methanol, 2:1). Then, the solution having yolk was agitated on magnetic stirrer at $200 \mathrm{rpm}$ for $1 \mathrm{~h}$. After agitation, the solution was sieved and $2.2 \mathrm{~mL}$ of distilled water was added and centrifuged at $1000 \mathrm{rpm}$ for $5 \mathrm{~min}$. After centrifugation, the upper layer was discarded. Then $1.5 \mathrm{~mL}$ of wash solution (chloroform, methanol, and water, $8: 4: 3$ ) was poured to each tube and mixed well and the upper layer was removed. This step was repeated twice. The remaining solution in the bottom layer was washed three times with wash solution and then transferred to a China dish and kept on the water bath for evaporation of solvents. The extracted lipids were recovered in small tubes. The egg yolk cholesterol was determined in the filtered sample by spectrophotometric method described by Rotenberg and Christensen [20] using chemistry analyzer (Map Lab Plus, Japan) at $546 \mathrm{~nm}$.
TABLE 1: Ingredient composition (\%) of layer rations with different levels of hemp seed.

\begin{tabular}{|c|c|c|c|c|}
\hline & HS-0 & HS-15 & HS-20 & HS-25 \\
\hline \multicolumn{5}{|l|}{ Ingredients (\%) } \\
\hline Hemp seed & 0 & 15 & 20 & 25 \\
\hline Corn & 51.25 & 37.95 & 39.75 & 41.25 \\
\hline Canola meal & 6 & 5 & 5 & 5 \\
\hline Soybean meal & 8 & 6 & 6 & 6 \\
\hline Fish meal & 4 & 4 & 4 & 4 \\
\hline Sunflower meal & 10 & 5 & 0 & 0 \\
\hline Corn gluten meal & 4 & 5 & 5 & 0 \\
\hline Soya oil & 4 & 3.3 & 1.5 & 0 \\
\hline Wheat bran & 0 & 6 & 6 & 6 \\
\hline Marble chips & 7 & 7 & 7 & 7 \\
\hline $\begin{array}{l}\text { Dicalcium } \\
\text { phosphate }\end{array}$ & 2 & 2 & 2 & 2 \\
\hline Molasses & 3 & 3 & 3 & 3 \\
\hline Lysine & 0.2 & 0.2 & 0.2 & 0.2 \\
\hline Methionine & 0.05 & 0.05 & 0.05 & 0.05 \\
\hline Salt & 0.15 & 0.15 & 0.15 & 0.15 \\
\hline Soda & 0.05 & 0.05 & 0.05 & 0.05 \\
\hline Coccidiostat & 0.05 & 0.05 & 0.05 & 0.05 \\
\hline Zinc bacitracin & 0.05 & 0.05 & 0.05 & 0.05 \\
\hline $\begin{array}{l}\text { Vitamin mineral } \\
\text { premix }^{1}\end{array}$ & 0.2 & 0.2 & 0.2 & 0.2 \\
\hline \multicolumn{5}{|l|}{$\begin{array}{l}\text { Calculated } \\
\text { nutritional } \\
\text { composition }\end{array}$} \\
\hline Dry matter (\%) & 88.86 & 88.80 & 88.65 & 88.38 \\
\hline $\begin{array}{l}\text { Metabolizable } \\
\text { energy }\left(\mathrm{Kcal} \mathrm{kg}^{-1}\right)\end{array}$ & 2916 & 2910 & 2911 & 2911 \\
\hline Crude protein (\%) & 17.05 & 17.00 & 17.09 & 17.10 \\
\hline Ether extract (\%) & 10.03 & 10.01 & 9.99 & 10.02 \\
\hline Fiber (\%) & 8.94 & 8.39 & 8.08 & 8.96 \\
\hline Ash (\%) & 10.36 & 10.95 & 10.78 & 10.82 \\
\hline Calcium (\%) & 3.52 & 3.51 & 3.52 & 3.52 \\
\hline $\begin{array}{l}\text { Phosphorus } \\
\text { available (\%) }\end{array}$ & 0.59 & 0.58 & 0.59 & 0.59 \\
\hline Linoleic acid (\%) & 1.39 & 3.95 & 6.70 & 8.56 \\
\hline Lysine (\%) & 0.85 & 0.88 & 0.87 & 0.89 \\
\hline Methionine (\%) & 0.40 & 0.40 & 0.40 & 0.41 \\
\hline Cysteine (\%) & 0.28 & 0.27 & 0.27 & 0.28 \\
\hline $\begin{array}{l}\text { Methionine + } \\
\text { cysteine (\%) }\end{array}$ & 0.73 & 0.69 & 0.71 & 0.72 \\
\hline Salt (\%) & 0.41 & 0.39 & 0.39 & 0.39 \\
\hline Threonine (\%) & 0.59 & 0.59 & 0.58 & 0.59 \\
\hline Tryptophan (\%) & 0.18 & 0.17 & 0.15 & 0.15 \\
\hline
\end{tabular}

${ }^{1}$ Providing per kg of diet: Mn $80 \mathrm{mg}$; Zn $60 \mathrm{mg}$; Fe $60 \mathrm{mg}$; Cu $5 \mathrm{mg}$; Co $0.2 \mathrm{mg}$; I $1 \mathrm{mg}$; Se $0.15 \mathrm{mg}$; choline chloride $200 \mathrm{mg}$; vitamin A $12000 \mathrm{IU}$; vitamin D3 $2400 \mathrm{IU}$; vitamin E $50 \mathrm{mg}$; vitamin $\mathrm{K} 34 \mathrm{mg}$; vitamin $\mathrm{B} 13 \mathrm{mg}$; vitamin B2 $6 \mathrm{mg}$; niacin $25 \mathrm{mg}$; calcium-d-pantothenate $10 \mathrm{mg}$; vitamin B6 $5 \mathrm{mg}$; vitamin B12 $0.03 \mathrm{mg}$; d-biotin $0.05 \mathrm{mg}$; folic acid $1 \mathrm{mg}$.

2.3. Fatty Acid Methyl Esters Preparation. For this purpose, $50 \mathrm{mg}$ of yolk was mixed with $1.5 \mathrm{~mL}$ of methanolic sodium hydroxide $(3 \mathrm{~N})$ and boiled at $100^{\circ} \mathrm{C}$ for $5 \mathrm{~min}$. After cooling, the residual lipids were collected in $2.5 \mathrm{~mL}$ of $14 \%$ boron trifluoride $\left(30 \mathrm{~min}\right.$ at $\left.80^{\circ} \mathrm{C}\right)$. Fatty acids methyl esters were 
TABLE 2: Mean \pm SE of cholesterol contents in eggs from hens consuming different levels of hemp seed $(n=3)$.

\begin{tabular}{lcc}
\hline $\begin{array}{l}\text { Experimental } \\
\text { groups }\end{array}$ & $\begin{array}{c}\text { Cholesterol } \\
(\mathrm{mg} / \mathrm{g} \text { of yolk })\end{array}$ & $\begin{array}{c}\text { Cholesterol } \\
(\mathrm{mg} / \mathrm{egg})\end{array}$ \\
\hline HS-0 & $19.27 \pm 0.01^{\mathrm{a}}$ & $281.13 \pm 2.30^{\mathrm{a}}$ \\
HS-15 & $16.91 \pm 0.01^{\mathrm{b}}$ & $255.67 \pm 1.03^{\mathrm{b}}$ \\
HS-20 & $14.29 \pm 0.01^{\mathrm{c}}$ & $224.11 \pm 2.02^{\mathrm{c}}$ \\
HS-25 & $11.65 \pm 0.01^{\mathrm{d}}$ & $190.71 \pm 0.28^{\mathrm{d}}$ \\
\hline$P$ value & 0.0001 & 0.0001 \\
\hline
\end{tabular}

Means in the same column with different superscripts are significantly different $(P<0.05)$

collected in $1 \mathrm{~mL}$ of hexane. For clear separation of hexane layer $5 \mathrm{~mL}$ of saturated salt $(400 \mathrm{~g}$ of $\mathrm{NaCL} / \mathrm{L}$ of water) solution was added, and the tubes were vortexed for 1$2 \mathrm{~min}$, followed by centrifugation at $800 \times \mathrm{g}$ for $5 \mathrm{~min}$. The top (hexane) layer was transferred into new GC vials. For completed separation of fatty acids methyl esters, $1 \mathrm{~mL}$ of hexane was again added to each tube and vortexed for 1$2 \mathrm{~min}$, followed by centrifugation $(800 \times \mathrm{g}$ for $5 \mathrm{~min}$ ) and the transfer of the hexane layer to the respective GC vials. The fatty methyl esters were analyzed by gas chromatography mass spectrometry (GC-MS; Trace GC Ultra, Thermo Fisher Scientific, Waltham, MA, USA) with fused silica capillary column $(50 \mathrm{~m} \times 0.250 \mathrm{~mm}$ and $0.2 \mu \mathrm{m}$ film thickness; Supleco, SP-2560; Supelco, Bellefonte PA, USA) using hydrogen as a carrier gas at a constant flow of $1.5 \mathrm{~mL} / \mathrm{min} .1 \mu \mathrm{L}$ of sample was injected into the GC with a split ratio of $1: 5$ as described by Khan et al. [21]. The flame ionization detector was set at $280^{\circ} \mathrm{C}$. The time-temperature program used started with an initial temperature of $140^{\circ} \mathrm{C}$ for $4 \mathrm{~min}$, increased $4^{\circ} \mathrm{C}$ per min to a final temperature of $240^{\circ} \mathrm{C}$, and held at this temperature for $20 \mathrm{~min}$ as reported earlier [22]. The fatty acids methyl esters were identified using external standards (S37, Supelco, Poole, Dorset, United Kingdom), and the fatty acids contents were calculated from the peak area of the corresponding FA in relation to the total area of all peaks.

2.4. Statistical Analyses. Data was statistically analyzed using standard procedure of ANOVA in completely randomized design. Least significant difference (LSD) test was used for separation of means. Statistical package (SAS) was used for these analyses [23]. $P$ value less than 0.05 was considered statistically significant.

\section{Results}

3.1. Cholesterol. Cholesterol (yolk plus egg) level decreased significantly $(P<0.05)$ with the increasing level of HS in the diet of laying birds. Higher cholesterol concentration was found in the control group while lowest concentration was recorded in group HS-25 (Table 2).

\subsection{Fatty Acid Profile of Egg}

3.2.1. Saturated Fatty Acids. Individual and total saturated fatty acids concentration is given in Table 3. Myristic acid and stearic acids concentration decreased significantly in HS-25 fed groups. Highest value of palmitic acid was recorded in the control group which decreased in HS- 15 followed by HS20 and HS-25.

3.2.2. Monounsaturated Fatty Acids. Total monounsaturated fatty acids decreased significantly $(P<0.05)$ by increasing HS level in the laying hens diets (Table 4). Highest value of Palmitoleic acid (C16:1) was recorded in the control group followed by HS- 25 and HS-20 while lowest concentration was recorded in HS-15 (Table 4). The highest value of oleic acid (C18:1) was also recorded in the control group. There were no differences between the oleic acid contents found in the eggs of the hens fed with HS diets.

3.2.3. Polyunsaturated Fatty Acids. Total polyunsaturated fatty acids increased significantly $(P<0.05)$ by increasing HS in the diets of laying birds (Table 4). Concentration of linoleic acid (C18:2) increased with the increasing level of HS up to $20 \%$. Highest concentration was recorded in HS-25. The highest value of g-linolenic acid was recorded in HS-20 and HS-25 and lowest in the control group. Linoleic acid (C18:2), g-linolenic acid (C18:3n6), linolenic acid (C18:3n3), eicosadienoic acid (C20:2n6), eicosatrienoic acid (C20:3n3), arachidonic acid (C20:4n6), EPA (C20:5n3), and DHA $(\mathrm{C} 22: 6 \mathrm{n} 3)$ increased significantly $(P<0.05)$ in the same groups. Eicosadienoic acid concentration was similar in HS-15 and HS-20. Eicosapentaenoic acid (EPA) (C20:5n3) content was highest in HS-25 group, showing no significant differences between all other groups.

Hens receiving $25 \%$ of HS in their diet had highest total omega-3 contents in their egg yolks (Table 5). The highest total omega-6 concentration was recorded in HS-20 and HS-25 groups (Table 5). Best omega- 6 to omega- 3 ratio was reported in HS- 25 and the poorest ratio was found in HS-0 and HS-15 (Table 5).

\section{Discussion}

In Canada, hemp seed is not recommended in poultry diet because of lacking of scientific evidence [24]. To date, information regarding the effect of hemp seed on egg yolk cholesterol and fatty acids profile in Rhode Island Red $\mathrm{x}$ Fyoumi laying hens has not been reported. In the present study, we found that fatty acids were modified by the addition of HS in the feed of layer. In addition, total cholesterol concentration in the egg yolk decreased by increasing hemp seed level in the diet. Hemp seed contains $\beta$-sitosterol (phytosterol) which is helpful in reducing hypercholesterolemia by blocking cholesterol absorption through crystallization and coprecipitation $[25,26]$. Moreover, phytosterols have lower hydrosolubility than cholesterol so it misplaces the cholesterol from intestinal micelles. This competition reduces the absorption rate of the cholesterol by limiting its ability to reach the absorption [27-29]. Phytosterols also can lower the hepatic cholesterol biosynthesis by downregulating enzyme activity such as those involved in the terpene synthesis and the 3-hydroxy-3-methylglutaryl-coenzyme A (HMGCoA) reductase, restricting the rate of cholesterol formation [30]. 
TABLE 3: Mean \pm SE of saturated fatty acid $(\mathrm{mg} / \mathrm{g})$ in eggs from hens fed with different levels of hemp seed $(n=3)$.

\begin{tabular}{lcccc}
\hline Experimental groups & Myristic $($ C14:0) & Palmitic (C16:0) & Stearic (C18:0) & Total SFA \\
\hline HS-0 & $0.71 \pm 0.06^{\mathrm{a}}$ & $55.95 \pm 1.94^{\mathrm{a}}$ & $19.03 \pm 0.22^{\mathrm{a}}$ & $75.68 \pm 0.01^{\mathrm{a}}$ \\
HS-15 & $0.43 \pm 0.02^{\mathrm{b}}$ & $42.18 \pm 0.86^{\mathrm{b}}$ & $16.17 \pm 0.66^{\mathrm{b}}$ & $58.78 \pm 0.00^{\mathrm{b}}$ \\
HS-20 & $0.40 \pm 0.02^{\mathrm{b}}$ & $34.60 \pm 2.05^{\mathrm{c}}$ & $16.00 \pm 0.90^{\mathrm{b}}$ & $51.01 \pm 0.01^{\mathrm{c}}$ \\
HS-25 & $0.46 \pm 0.03^{\mathrm{b}}$ & $32.51 \pm 2.90^{\mathrm{c}}$ & $14.21 \pm 0.52^{\mathrm{b}}$ & $47.18 \pm 0.01^{\mathrm{d}}$ \\
\hline$P$ value & 0.0010 & 0.0002 & 0.0041 & 0.0000 \\
\hline
\end{tabular}

Means in the same column with different superscripts are significantly different $(P<0.05)$.

TSFA: total saturated fatty acids.

TABLE 4: Mean \pm SE of unsaturated fatty acid $(\mathrm{mg} / \mathrm{g})$ in eggs from hens fed with different levels of hemp seed $(n=3)$.

\begin{tabular}{|c|c|c|c|c|c|}
\hline \multirow{2}{*}{ Unsaturated fatty acids } & \multicolumn{5}{|c|}{ Levels of hemp seed } \\
\hline & HS-0 & HS-15 & HS-20 & HS-25 & $P$ value \\
\hline Palmitoleic acid (C16:1) MUFA & $4.87 \pm 0.19^{\mathrm{a}}$ & $2.89 \pm 0.07^{\mathrm{ab}}$ & $2.16 \pm 0.18^{c}$ & $2.42 \pm 0.13^{\mathrm{b}}$ & 0.0001 \\
\hline Oleic acid (C18:1) MUFA & $65.67 \pm 1.36^{\mathrm{a}}$ & $54.45 \pm 3.3^{\mathrm{b}}$ & $52.51 \pm 1.7^{\mathrm{b}}$ & $51.00 \pm 0.94^{\mathrm{b}}$ & 0.0040 \\
\hline Linoleic acid (C18:2) PUFA & $30.08 \pm 1.22^{c}$ & $54.05 \pm 1.3^{\mathrm{b}}$ & $57.57 \pm 0.77^{\mathrm{a}}$ & $59.10 \pm 0.35^{\mathrm{a}}$ & 0.0001 \\
\hline g-linolenic acid (C18:3n6) PUFA & $0.10^{c} \pm 0.00^{c}$ & $0.22 \pm 0.02^{\mathrm{b}}$ & $0.27 \pm 0.01^{\mathrm{a}}$ & $0.31 \pm 0.01^{\mathrm{a}}$ & 0.0001 \\
\hline Linolenic acid (C18:3n3) PUFA & $1.22 \pm 0.09^{\mathrm{d}}$ & $4.29 \pm 0.03^{c}$ & $6.34 \pm 0.08^{\mathrm{b}}$ & $9.16 \pm 0.35^{\mathrm{a}}$ & 0.0001 \\
\hline Eicosadienoic acid (C20:2n6) PUFA & $0.10 \pm 0.00^{c}$ & $0.29 \pm 0.01^{\mathrm{b}}$ & $0.33 \pm 0.02^{\mathrm{ab}}$ & $0.35 \pm 0.01^{\mathrm{a}}$ & 0.0001 \\
\hline Eicosatrienoic acid (C20:3n3) PUFA & $0.10 \pm 0.00^{c}$ & $0.13 \pm 0.01^{b}$ & $0.11 \pm 0.01^{\mathrm{bc}}$ & $0.20 \pm 0.00^{\mathrm{a}}$ & 0.0001 \\
\hline Arachidonic acid (C20:4n6) PUFA & $3.43 \pm 0.12$ & $3.42 \pm 0.09$ & $3.50 \pm 0.09$ & $3.77 \pm 0.09$ & 0.1044 \\
\hline EPA (C20:5n3) PUFA & $0.00 \pm 0.00^{\mathrm{b}}$ & $0.10 \pm 0.00^{\mathrm{b}}$ & $0.18 \pm 0.02^{\mathrm{b}}$ & $0.50 \pm 0.12^{\mathrm{a}}$ & 0.0016 \\
\hline DHA (C22:6n3) PUFA & $1.33 \pm 0.09^{c}$ & $3.27 \pm 0.12^{\mathrm{b}}$ & $3.65 \pm 0.03^{b}$ & $5.26 \pm 0.44^{\mathrm{a}}$ & 0.0001 \\
\hline MUFA (total) & $70.54 \pm 0.01^{\mathrm{a}}$ & $56.34 \pm 0.01^{\mathrm{b}}$ & $54.67 \pm 0.01^{\mathrm{c}}$ & $53.42 \pm 0.01^{\mathrm{d}}$ & 0.0000 \\
\hline PUFA (total) & $36.36 \pm 0.01^{\mathrm{d}}$ & $65.77 \pm 0.01^{\mathrm{c}}$ & $71.96 \pm 0.00^{\mathrm{b}}$ & $78.65 \pm 0.00^{\mathrm{a}}$ & 0.0000 \\
\hline
\end{tabular}

Means in the same column with different superscripts are significantly different $(P<0.05)$.

MUFA: monounsaturated fatty acid; PUFA: polyunsaturated fatty acid; EPA: eicosapentaenoic acid; DHA: docosahexaenoic acid.

TABle 5: Mean \pm SE of total $\omega-3(\mathrm{mg} / \mathrm{g})$, total $\omega-6(\mathrm{mg} / \mathrm{g})$, and $\omega$ $6: \omega-3$ in eggs from hens consuming different levels of hemp seed $(n=3)$.

\begin{tabular}{lccc}
\hline Experimental groups & Total $\omega-3$ & Total $\omega-6$ & $\omega-3: \omega-6$ \\
\hline HS-0 & $2.66 \pm 0.17^{\mathrm{d}}$ & $33.71 \pm 1.33^{\mathrm{c}}$ & $16.83 \pm 1.99^{\mathrm{a}}$ \\
HS-15 & $7.79 \pm 0.13^{\mathrm{c}}$ & $57.97 \pm 1.24^{\mathrm{b}}$ & $8.44 \pm 0.07^{\mathrm{a}}$ \\
HS-20 & $10.29 \pm 0.09^{\mathrm{b}}$ & $61.67 \pm 0.73^{\mathrm{a}}$ & $6.19 \pm 0.11^{\mathrm{bc}}$ \\
HS-25 & $15.11 \pm 0.81^{\mathrm{a}}$ & $63.52 \pm 0.29^{\mathrm{a}}$ & $4.22 \pm 0.25^{\mathrm{c}}$ \\
\hline$P$ value & 0.0001 & 0.0001 & 0.0001 \\
\hline
\end{tabular}

Means in the same column with different superscripts are significantly different $(P<0.05)$.

$\omega$-3: omega-3 or linolenic acid; $\omega$-6: omega- 6 or linoleic acid.

Hence it is inferred that HS lowers egg yolk cholesterol due to its high phytosterol and unsaturated fatty acid contents. Similar findings were also reported previously [18].

Saturated fatty acids like myristic acid (C14:0), palmitic acid (C16:0), and stearic acid (C18:0) decreased in HS fed groups. HS contains high level of unsaturated fatty acids and low level of saturated fatty acid $[10,31]$. In agreement with our results, Silversides et al. [17] reported lower percentage of palmitic acid (C16:0) by increasing HS in the diet. Increasing PUFA in the diet decreases monounsaturated fatty acid contents of egg yolk. Similarly, HS contains omega-3 fatty acids [32] and increased intake of omega-3 fatty acids in the diet decreases MUFA level of egg yolks. The results of the current study are supported by the findings of Schwab et al. [32].

Diets having high level of linoleic $(\omega-6)$ fatty acid result in increased level of linoleic $(\omega-6)$ fatty acid content in the egg yolk [6]. HS contains fair amounts of linoleic acid [10] which may be responsible for increasing yolk linoleic content. Our results are in line with Silversides et al. [17] who recorded higher values of linoleic acid by feeding HS meal to hens. Gamma-linolenic (C18:3n6) concentration increased by increasing HS level in the diet which is easily absorbed from small intestines [10]. HS contains linolenic acid [32] which might have increased the level of egg yolk linolenic acid. Silversides et al. [17] reported higher values of linolenic acid by giving HS meal to laying hens.

Johansson [18] and Goldberg et al. [33] reported no significant increase in arachidonic acid (C20:3n3) in the egg yolk of birds fed with HS as compared to the control. Eicosapentaenoic acid (EPA) (C20:5n3) was significantly affected by $\mathrm{HS}$ levels in the diet of laying birds. In liver, linolenic acid is converted to EPA (C20:5n3) by delta-5 desaturase and elongase activity through a metabolic pathway which may be responsible for higher EPA values in the egg yolk. DHA concentration in egg yolk increases with increasing HS concentration in the diet being highest in group having $25 \%$ HS. HS contains fair amount of linolenic acid [34]. Similar results were also reported elsewhere $[18,32,35]$. 
Hens receiving 25\% of HS in their diet had the highest total omega- 3 and omega- 6 contents in their egg. This increase in total omega- 3 concentration may be due to the linolenic acid content in the HS and its conversion to long chain fatty acid in the body of the hen [34]. A relationship exists between dietary and egg yolk linoleic acid contents [6]. The level of linoleic acid (n-6), g-linolenic acid (n-6), and eicosadienoic acid $[10,31]$ in HS may increase the total omega- 6 contents in egg yolk by direct absorption from intestine. Moreover, conversion of linoleic acid to its long chain components in the liver like g-linolenic acid and arachidonic acid may also increase linoleic acid concentration in the egg yolk. The ratio of $\omega-3$ to $\omega-6$ is the lowest in HS- 25 which is beneficial for public health.

\section{Conclusion}

From the present study, we concluded that inclusion of $25 \%$ hemp seeds into the laying hens diet improved cholesterol and fatty acids profile in egg yolk.

\section{Conflict of Interests}

The authors declare that there is no conflict of interests regarding the publication of this paper.

\section{References}

[1] A. Sultan, H. Obaid, S. Khan, I. ur Rehman, M. K. Shah, and R. U. Khan, "Nutritional effect of flaxseeds on cholesterol profile and fatty acid composition in egg yolk," Cereal Chemistry, vol. 92, no. 1, pp. 50-53, 2015.

[2] J. E. Kinsella, E. Frankel, B. German, and J. Kanner, "Possible mechanisms for the protective role of antioxidants in wine and plant foods," Food Technology, vol. 47, pp. 85-89, 1993.

[3] R. Ansari, A. Azarbayejani, S. Ansari, S. Asgari, and A. Gheisari, "Production of egg enriched with omega-3 fatty acids in laying hens," ARYA Atherosclerosis, vol. 1, no. 4, pp. 242-246, 2006.

[4] H. Yalçýn, M. K. Ünal, and H. Basmacýoolu, "The fatty acid and cholesterol composition of enriched egg yolk lipids obtained by modifying hens' diets with fish oil and flaxseed," Grasas $y$ Aceites, vol. 58, no. 4, pp. 372-378, 2007.

[5] F. J. Bavelaar and A. C. Beynen, "The relation between diet, plasma cholesterol and atherosclerosis in pigeons, quails and chickens," International Journal of Poultry Science, vol. 3, no. 11, pp. 671-684, 2004.

[6] A. C. Beynen, "Fatty acid composition of eggs produced by hens fed diets containing groundnut, soya bean or linseed," NJASWageningen Journal of Life Sciences, vol. 52, no. 1, pp. 3-10, 2004.

[7] R. U. Khan, F. R. Durrani, N. Chand, and H. Anwar, "Influence of feed supplementation with Cannabis sativa on quality of broilers carcass," Pakistan Veterinary Journal, vol. 30, no. 1, pp. 34-38, 2010.

[8] E. Small, "Practical and natural taxonomy for cannabis," in The Species Problem in Cannabis, E. Small, Ed., vol. 1, pp. 171-211, Corpus, Toronto, Canada, 1979.

[9] R. U. Khan, F. R. Durrani, N. Chand, S. Naz, F. A. Farooqi, and M. N. Manzoor, "Effect of Cannabis sativa fortified feed on muscle growth and visceral organs in broiler chicks," International
Journal of Biology and Biotechnology, vol. 6, no. 3, pp. 179-182, 2009.

[10] J.-L. Deferne and D. W. Pate, "Hemp seed oil: a source of valuable essential fatty acids," Journal of the International Hemp Association, vol. 3, no. 1, pp. 4-7, 1996.

[11] F. Grotenhermen, "Pharmacokinetics and pharmacodynamics of cannabinoids," Clinical Pharmacokinetics, vol. 42, no. 4, pp. 327-360, 2003.

[12] A. J. Hampson, M. Grimaldi, M. Lolic, D. Wink, R. Rosenthal, and J. Axelrod, "Neuroprotective antioxidants from marijuana," Annals of the New York Academy of Sciences, vol. 899, pp. 274282, 2000.

[13] Y. Konca, H. Yalcin, M. Karabacak, M. Kaliber, and F. Z. Durmuscelebi, "Effect of hempseed (Cannabis sativa L.) on performance, egg traits and blood biochemical parameters and antioxidant activity in laying Japanese Quail (Coturnix coturnix japonica)," British Poultry Science, vol. 55, no. 6, pp. 785-794, 2014.

[14] U. Erasmus, Fats That Heal, Fats That Kill, Alive Books, Burnaby, Canada, 2nd edition, 1999.

[15] S. A. Mohamed, M. E. S. Barri, and S. M. E. Khojali, "The effect of feeding marine fishmeal on fatty acids profile, plasma lipids profile and production traits of layers," Research Opinions in Animal \& Veterinary Sciences, vol. 2, no. 6, pp. 388-392, 2012.

[16] A. P. Simopoulos, "Fatty acids," in Functional Foods: Designer Foods, Pharma foods, Nutraceuticals, I. Goldberg, Ed., pp. 355392, Chapman \& Hall, New York, NY, USA, 1994.

[17] F. G. Silversides, K. L. Budgell, and M. R. Lefrancois, "Effect of feeding HS meal to laying hens," APRI Factsheet 16, Atlantic Poultry Research Institute, 2002.

[18] A. Johansson, Effects of genotype age and feed on the fat components of egg yolk [Ph.D. thesis], Department of Animal Nutrition and Management, Swedish University of Agricultural Sciences, Uppsala, Sweden, 2010.

[19] J. Folch, M. Lees, and G. H. Sloane-Stanley, "A simple method for the isolation and purification of total lipides from animal tissues," The Journal of Biological Chemistry, vol. 226, no. 1, pp. 497-509, 1957.

[20] S. Rotenberg and K. Christensen, "Spectrophotometric determination of total and free cholesterol in egg yolk and animal tissues," Acta Agriculturae Scandinavica, vol. 26, no. 2, pp. 9498, 2009.

[21] N. A. Khan, M. W. Farooq, M. Ali et al., "Effect of species and harvest maturity on the fatty acids profile of tropical forages," Journal of Animal and Plant Science, vol. 25, no. 3, pp. 739-746, 2015.

[22] N. A. Khan, J. W. Cone, and W. H. Hendriks, "Stability of fatty acids in grass and maize silages after exposure to air during the feed out period," Animal Feed Science and Technology, vol. 154, no. 3-4, pp. 183-192, 2009.

[23] SAS, SAS/STAT Software: Changes and Enhancements Through Release 6.11, SAS Institute, Cary, NC, USA, 1996.

[24] N. Gakhar, E. Goldberg, M. Jing, R. Gibson, and J. D. House, "Effect of feeding hemp seed and hemp seed oil on laying hen performance and egg yolk fatty acid content: evidence of their safety and efficacy for laying hen diets," Poultry Science, vol. 91, no. 3, pp. 701-711, 2012.

[25] F. H. Mattson, S. M. Grundy, and J. R. Crouse, "Optimizing the effect of plant sterols on cholesterol absorption in man," The American Journal of Clinical Nutrition, vol. 35, no. 4, pp. 697700, 1982. 
[26] T. Malini and G. Vanithakumari, "Rat toxicity studies with $\beta$ sitosterol," Journal of Ethnopharmacology, vol. 28, no. 2, pp. 221234, 1990.

[27] E. A. Trautwein, G. S. M. J. E. Duchateau, Y. Lin, S. M. Mel'nikov, H. O. F. Molhuizen, and F. Y. Ntanios, "Proposed mechanisms of cholesterol-lowering action of plant sterols," European Journal of Lipid Science and Technology, vol. 105, no. 3-4, pp. 171-185, 2003.

[28] R. E. Ostlund Jr., "Phytosterols and cholesterol metabolism," Current Opinion in Lipidology, vol. 15, no. 1, pp. 37-41, 2004.

[29] G. Brufau, M. A. Canela, and M. Rafecas, "Phytosterols: physiologic and metabolic aspects related to cholesterol-lowering properties," Nutrition Research, vol. 28, no. 4, pp. 217-225, 2008.

[30] E. K. Asem and F. Hertelendy, "Influence of follicular maturation on 3-hydroxy-methylglutaryl coenzyme A reductase activity in hen granulosa cells," Journal of Reproduction and Fertility, vol. 79, no. 1, pp. 215-221, 1987.

[31] J. C. Callaway and T. T. Laakkonen, "Cultivation of cannabis oil seed varieties in Finland," Journal of International Hemp Association, vol. 3, no. 1, pp. 32-34, 1996.

[32] S. Schwab, S. Schwarz, M. Spranger, E. Keller, M. Bertram, and W. Hacke, "Moderate hypothermia in the treatment of patients with severe middle cerebral artery infarction," Stroke, vol. 29, no. 12, pp. 2461-2466, 1998.

[33] E. M. Goldberg, N. Gakhar, D. Ryland, M. Aliani, R. A. Gibson, and J. D. House, "Fatty acid profile and sensory characteristics of table eggs from laying hens fed hempseed and hempseed oil," Journal of Food Science, vol. 77, no. 4, pp. S153-S160, 2012.

[34] S. F. O. Keefe, "Nomenclature and classification of lipids," in Food Lipids; Chemistry, Nutrition, and Biotechnology, C. C. Akoh and D. B. Min, Eds., pp. 5-6, Marcel Dekker, New York, NY, USA, 2002.

[35] R. H. Ayerza and W. Coates, "Dietary levels of chia: influence on hen weight, egg production and sensory quality, for two strains of hens," British Poultry Science, vol. 43, no. 2, pp. 283-290, 2002. 

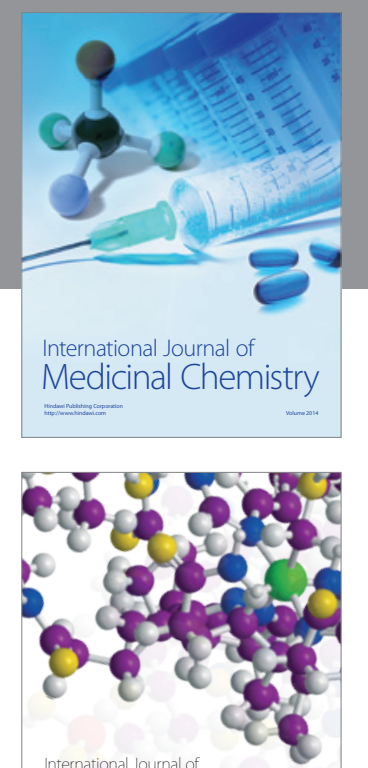

\section{Carbohydrate} Chemistry

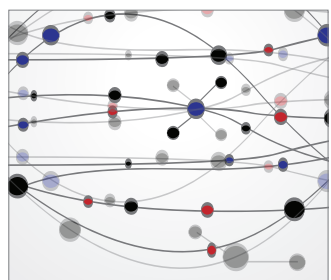

The Scientific World Journal
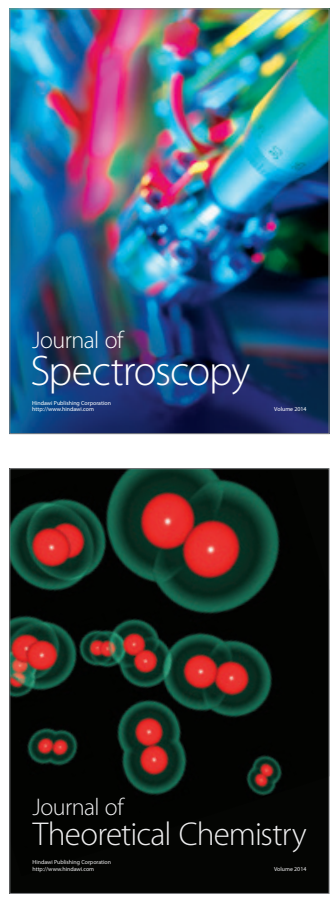
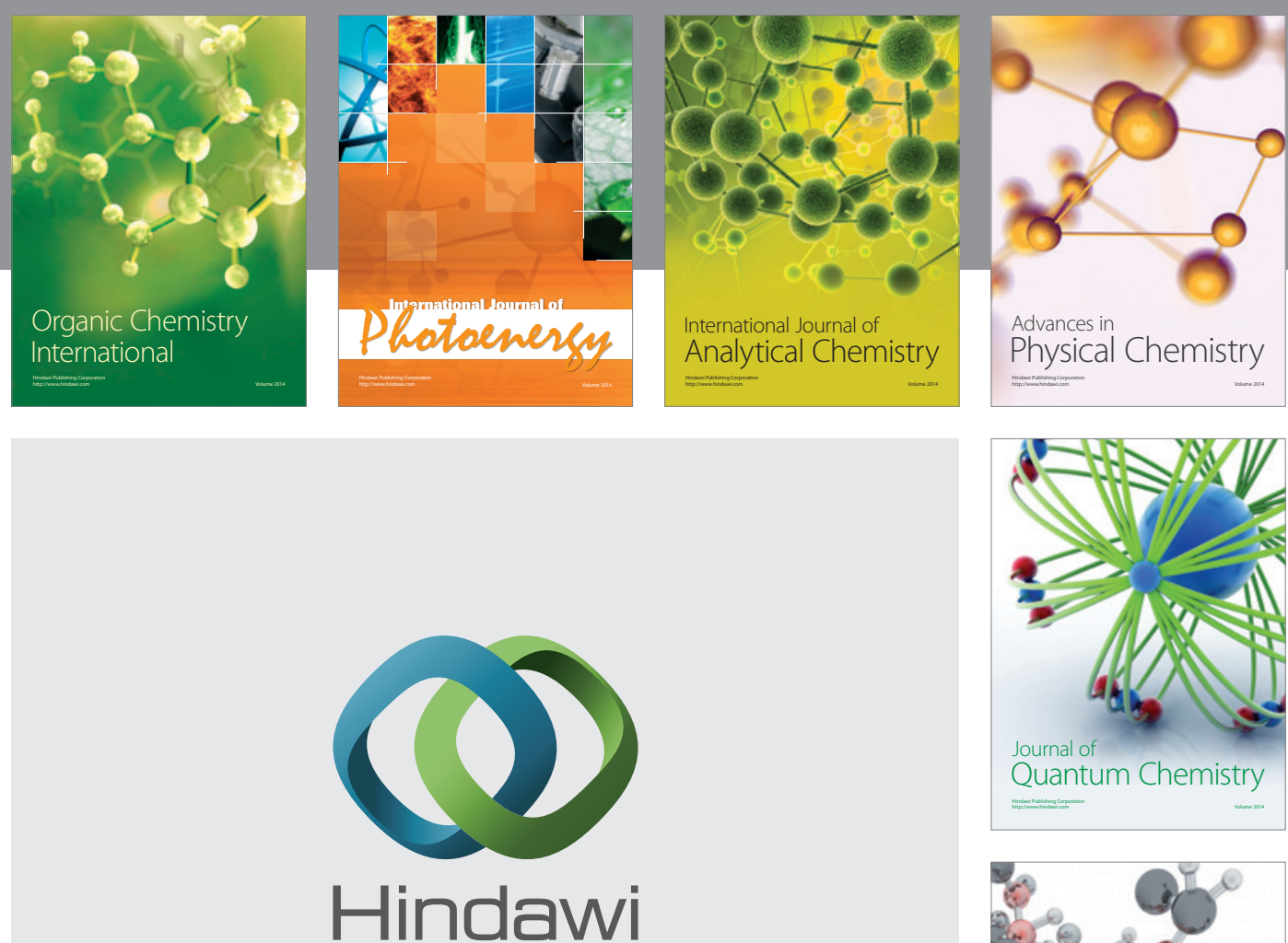

Submit your manuscripts at

http://www.hindawi.com

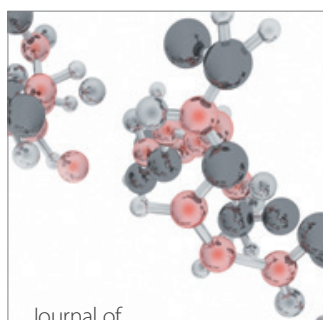

Analytical Methods

in Chemistry

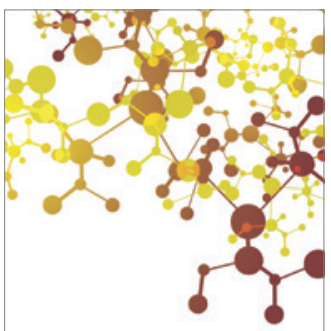

Journal of

Applied Chemistry

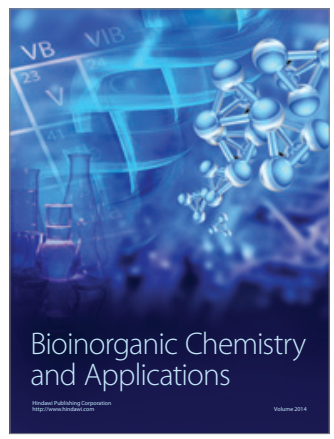

Inorganic Chemistry
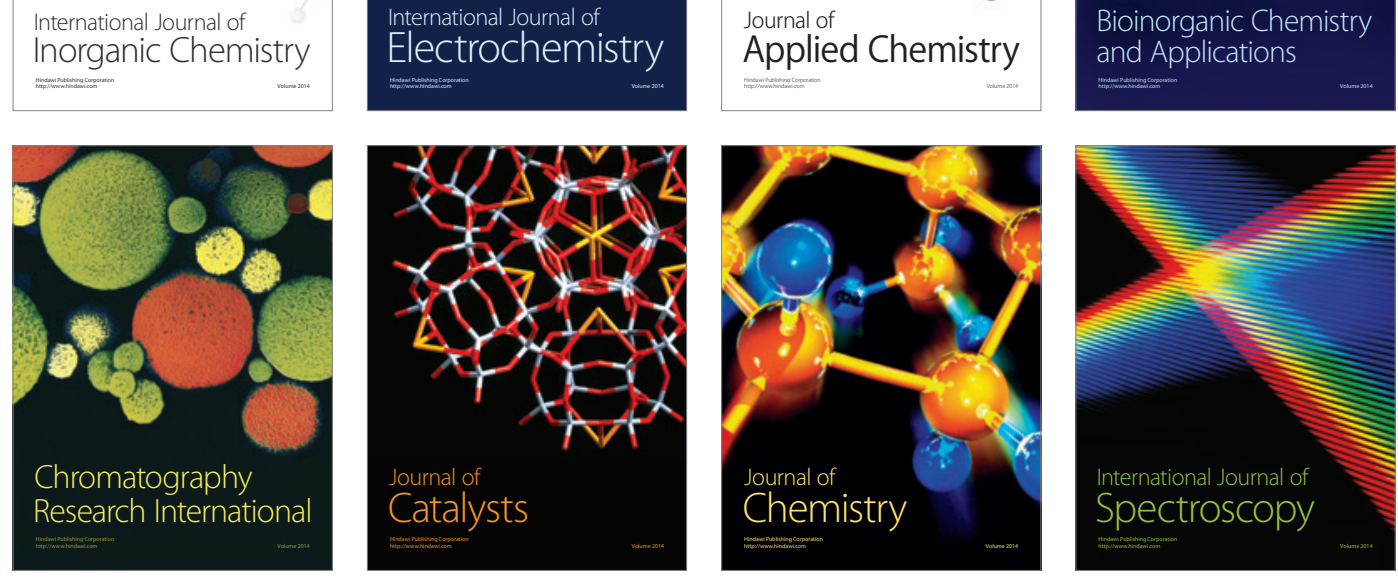